REVIEW

\section{PHYSIOTHERAPY AND THE GROWING CHILD}

Edited by: Yvonne R Burns and Julie MacDonald

Pub. WB Saunders Company Ltd (1996) ISBN: 0-7020-1942-9

$\mathrm{T}$ his book gives a holistic approach to all aspects of paediatric physiotherapy. The fact that there are numerous contributors from all over the world lends its credibility in a wide field. The book is well laid out with many appropriate photographs and diagrams to illustrate the text.

Extensive use is made of case histories and "Thought Provokers" which encourage clinical problem solving. These two features make the book particularly valuable for students who still lack clinical experience.

The book is divided into eight sections: Section A attempts to alert physiotherapists to the fact that more than just the principles of physiotherapy need to be implemented in treatment programmes. As the author so aptly puts it "Movement disorders, congested chests, fractured limbs and so on do not occur in the abstract. They occur in people who live in families, that belong to networks of extended family and friends, and are operative within a community and social setting which has particular beliefs, conventions, laws and policies". Case studies of four different children are used to clearly bring home the need for a holistic approach.

In section B growth and development are discussed with reference to the understanding of physiotherapy assessment, diagnosis and

\section{Essential Reading for all Healthcare Professionals}

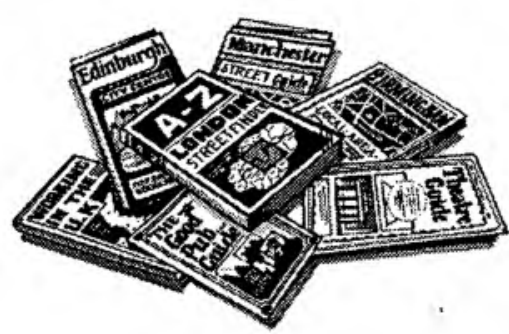

For your best route to working in Britoin os a short/long-term locum, Reed Paramedic Personnel is your number one choice, with hundreds of assignments throughout the UK. We can help you map out your working plans to fit in with your itinerary - and you can be sure that our knowledge is unrivalled, as all our consultants are trained healthcare professionals themselves.

Call us before you arrive and you'll be surprised at how helpful we can be:

- Top rates of pay

-Assistance with UK registration fees

- Help with tax and bahk account

-Advice on all employment needs

- Payment for professional development

- Accommodation arranged

- Advice on work permits

- Reverse charge calls accepted

If you would like to make your thip a genuine learning experience, contact us at Fairgate House, 78 New Oxford Street, London WCIA 1 HB. Tol: +44 (0)17i 6373155 . Fax: +44 (0) 1716372979. Web site: hitp://www.reed co.uk

YOUR GUIDE TO SUCCES S management. There are chapters on: birth to two years, two to six years, primary school child to adolescence and on intra-uterine differentiation and growth of the neuromusculoskeletal system.

A chapter is also included on common developmental anomalies. We feel the section gives a very good overview with sufficient information and plenty of references if further details are required.

In section $\mathrm{C}$ the principles and purposes of the assessment as well as the varying details, such as age and background, are discussed. The basic assessment process: history, observation, testing, recording and treatment planning is presented. Some specific types of assessments currently used are outlined and well tabulated. A short chapter on evaluating outcome stresses and the need to ask hard questions relating to the outcomes actually obtained and the real costs involved in achieving them is invaluable.

In section $\mathrm{D}$ the need for clinical reasoning and problem solving for the individual child is outlined. Basic principles including respect for the infant/child as an individual as well as showing respect for the family are tabulated. An outline of techniques used by physiotherapists in neuromusculoskeletal problems is fully tabulated.

Physiotherapy services for pre and school aged children covers such topics as: early intervention-team approaches, school, hospital-community and rural services. Aids and orthotics as well as gait analysis are also thoroughly discussed.

Section E: This section is divided into a section on the neonate and infant, the young child and the adolescent. Physiotherapy techniques are well described and specific problems like Cystic Fibrosis and bronchopulmonary dysplasia are discussed in fair detail. Issues of independence and control in adolescence are also pertinent.

Section F: The section on neonates and infants stresses the importance of individual comprehensive assessment and treatment. Specific musculoskeletal problems in this age group are presented. Common sport injuries unique to the athlete who is immature skeletally are also discussed.

Section G: Neurological, neuromuscular and developmental conditions from infancy to adolescence is discussed. In discussing the infant, again support of the parents and their education is emphasised.

In the section on children conditions the following conditions are discussed: Cerebral Palsy, Down's Syndrome Spina Bifida and Acquired brain injury.

Section H: In these closing chapters severe and multiple disability is shown to be an area where the physiotherapist can play an extensive role with children, families and coworkers. There are chapters on long-term disability; progressive neuromuscular disorders; the abused or neglected child and the disabled child in countries with minimal rehabilitation resources, including thought provoking information on community-based rehabilitation.

\section{IN SUMMARY}

We feel the book achieves its aim: "to provide the student and graduate physiotherapists as well as those involved in teaching physiotherapy, with an up-to-date resource which addresses the unique and special characteristic of working with children and their families".

J Zucci B.Sc. (Physio) Wits

J Potterton B.Sc. (Physio) 